\title{
Menstrual disorders: The implications on health and academic activities of female undergraduates in a federal university in Nigeria
}

\author{
Adekemi Eunice Olowokere, Monisola O. Oginni, Aanuoluwapo O Olajubu, Augusta E. William, \\ Omolola O. I rinoye
}

Department of Nursing Science, Obafemi Awolowo University, Ile-Ife, Nigeria.

Correspondence: Adekemi E. Olowokere. Address: Department of Nursing Science, Obafemi Awolowo University, Ile-Ife, Nigeria. Email: ayaolowo@yahoo.com

Received: December 11, 2013

DOI : $10.5430 /$ jnep.v4n5p126

Accepted: January 25, $2014 \quad$ Online Published: March 25, 2014

URL: http://dx.doi.org/10.5430/jnep.v4n5p126

\begin{abstract}
Menstruation is a natural phenomenon in a female who has reached the age of puberty. However, it is often associated with some discomforts which may affect women's health and academic activities of students. The study assessed the knowledge, management of menstrual disorders and the health and academic implications on young female undergraduates using a descriptive cross sectional design. A sample of 400 female undergraduates participated in the study. Data was collected using a 72-item semi structured questionnaire. Data collection lasted for two weeks and analysis was done using descriptive and inferential statistics at 0.05 level of significance. Result showed that $61 \%(\mathrm{n}=244)$ had good knowledge of menstrual disorders and its management. Most prevalent menstrual disorders found in the study was dysmenorrhoea. Missing school was the highest academic effect recorded $(64.5 \%, \mathrm{n}=258)$ while Dizziness $(51 \%, \mathrm{n}=$ 204) was the highest health implication recorded. A significant association was found between dysmenorrhoea and school absenteeism $\left(\chi^{2}=65.7, P<.05\right)$. The study reiterated the need for early educational programme that will assist the female undergraduates to cope well with menstrual disorders without any effect on their health and academics.
\end{abstract}

\section{Key words}

Menstruation, Menstrual disorders, Dysmenorrhoea, Female undergraduates, Nigeria

\section{Introduction}

The outset of menstruation is the most striking event in the whole process of female puberty ${ }^{[1]}$. Menstruation is a physiological process that occurs in females, which involves periodic and cyclical shedding of endometrium accompanied by loss of blood. This monthly experience by females adds a powerful tool to the assessment of normal development and the exclusion of pathological conditions among them, and it is one of the determinants of a woman's reproductive health ${ }^{[2-5]}$.

The menstrual cycle relies on action and interaction of hormones released from hypothalamus-pituitary and ovaries, and their effect on the endometrium. Normal menstrual pattern is such that age at menarche is less than 16 years, length of menstrual cycle between 24-32 days, the length of flow 3-7 days and amount of flow $\leq 80 \mathrm{~mL}{ }^{[6]}$. As important as menstruation is to human reproduction, it may be accompanied with varying disorders which can affect the quality of life of adolescents and young adult, and can also be indicators of serious underlying problems ${ }^{[7]}$. 
Disorders of menstruation include menstrual cycle irregularities (of duration or length), hyper-or hypomenorrhoea, poly-or oligomenorrhoea, dysmenorrhoea, amenorrhoea, menorrhagia and premenstrual syndrome (PMS) ${ }^{[8]}$. The disorders in cycles or its irregularities are major gynaecological problems among women (adolescents inclusive) in their reproductive years and a major source of anxiety to them and their family ${ }^{[9,10]}$. Previous studies also show a high prevalence of one or more types of menstrual irregularity among female students and that these problems affect the women's social activities and school attendance ${ }^{[7,11,12]}$. For example, studies have associated menstrual disorders with one of those common causes of psychological stress, regular absenteeism among young women in schools, work places, sports participation and other public functions ${ }^{[2,6,7,10,11,13]}$. A study have also shown that not less than $10 \%$ of menstruating young women are incapacitated for up to three days all because of monthly menstrual disorders ${ }^{[14]}$. Female undergraduates may possess little understanding of management of menstrual disorders. As a result of this, they develop a feeling of fear towards the last days to the onset of their monthly period because of the pain and discomfort that they have experienced previously. Due to debilitation experienced by most students, they are unable to carry on with their daily activities and may end up missing a class or more.

As some of these students are ignorant of the appropriate approach to the management of menstrual disorders, others may be aware but fail to adopt them as a result of some personal beliefs which are strongly adhered to or beliefs of others which were adopted at a particular time. Past studies in this area have also posited that information on a woman's menstrual pattern will aid in clinical evaluation of gynaecological problems and will make womanhood easier for adolescent women and adults ${ }^{[7,15]}$. Majority of the undergraduate females are usually within the adolescent and adulthood period where they face a lot of challenges relating to puberty and mastery of reproductive life issues. Such challenges may diminish their opportunities for successful educational and psychosocial health during this period of growth. Therefore, determining the academic and health challenges associated with menstruation is a prerequisite for planning interventions that seek to improve the management of menstrual disorders among female students.

The study was designed to determine: (a) the knowledge of female undergraduates on menstrual disorders and associated factors; (b) prevalence of menstrual disorders; (c) management strategies adopted by respondents to relief or treat menstrual disorders; and (d) effect of menstrual disorders on health and academic activities of the respondents. The information obtained from the study is expected to guide the school nurses in providing information and counselling to young females to develop proper knowledge of menstruation, the associated disorders and their management. This will go a long way in assisting them to adapt successfully with menstruation such that they can function effectively as regard their health and academics endeavours.

\section{Conceptual perspective}

Roy Adaptation Model (RAM) forms the conceptual framework underpinning this study. According to Roy, people are adaptive system(s) constantly growing and developing within a changing environment. A person's health or functioning can be described as a reflection of this interaction or adaptation ${ }^{[16]}$. The model assumes that a person is a bio-psychosocial being in constant interaction with a changing or dynamic environment. This means that the interaction requires use of adaptive mechanisms to conserve energy and maintain equilibrium. As female adolescents reach the age of puberty, they need to adjust to physiological changes such as menstruation. The factors influencing a person's adaptation level are called stimuli. Three different types of stimuli are particularly important in relation to the planning and provision of nursing intervention; foci stimuli, immediately surrounding a person e.g. health information from nurses, health care professionals or other materials used to deliver health care services including reproductive health services. Contextual stimuli are linked to the context in which focal stimuli are present. This can include advice from peers, parents and personal beliefs and attitudes about menstruation. Residual stimuli, on the other hand, are derived from people's previous experience, including that of health care such as visits to hospital.

Together, focal, contextual and residual stimuli establish the adaptation level characteristic of a person. This adaptation level in turn determines how the person responds to new stimuli. Two main types of responses are possible: Adaptive responses, which promote wellbeing. In the context of this study, the students are able to adjust to menstruation such that their health and academics are not affected among other consequences. The other response is the ineffective responses, 
which do not lead to these outcomes. These responses can be of four main types or as RAM puts it, fall within one of the four adaptive modes which are physiological, self-concept, role function and interdependency.

The basic physiological needs mentioned by Roy are essential for female undergraduates to cope successfully with menstruation. These include knowledge of strategies such as exercise and rest, nutrition, good elimination pattern, fluid and electrolytes balance, adequate oxygenation, circulation and protection against infection, including skin integrity. Self-concept describes the physical, personal and interpersonal needs of an individual that need to be met to maintain a state of adaptation. Role mastery/function expresses the aspect of the individual position in society. For example, as a female it is expected that a woman tolerate menstruation to be able to fulfil the role of reproduction, and that she adapts to any activities that will assist her in fulfilling this role effectively. An interdependence relation is the ability of the individual to achieve comfortable balance between dependence and independence. For example, female students must know when to seek help from health professionals regarding menstrual disorders and to attain wellness during the period. She must also learn to develop necessary confidence overtime to be in control of this monthly experience so as not to be totally dependent on others.

The purpose of nursing, according to Roy, is to change the stimuli to promote health in all life processes in the pursuit of higher level of wellness. In order to do this, much of the nurse's work aims to promote adaptive responses to any alterations in the four adaptive modes. For example in this study, the role of the nurse is to promote female undergraduates' adaptation to physiological alterations as a result of menstruation by providing necessary information on strategy that will enhance their health during this period without any effect on their health and academics. Menstruation is an inevitable physiological experience in female, but associated with a lot of inconveniences, ranging from irritability to weakness and a breakdown in the health of the woman most especially among teenagers and youth. This causes redundancy and incapacitation to those with such experiences.

Empowering the students with information on menstruation and its management by school nurses (foci stimuli) will assist the students to be adequately prepared to welcome menstruation every month. This can be done by making certain adjustments on their lifestyle thereby decreasing the strength of unwanted effects of menstrual disorders. Such adjustments can come in the form of taking pain relieving drugs, modifying diets, engagement in exercise, to mention but a few. The students could also be taught to engage in activities which could divert their attention from the inconveniences created by menstrual disorders (diversional therapy). Students would also be informed about possible deviations from normal and the actions to take in terms of seeking help. This would go a long way in helping them to adapt effectively to the changes in their system during menstrual period or act up when deviations occur.

\section{Materials and methods}

Using a descriptive cross-sectional design, the study examined the knowledge, health and academic implications of menstrual disorders among female university students. Sample for the study was determined using Yamane formula ${ }^{[17]}$, $\mathrm{n}=\mathrm{N} / 1+\mathrm{N}(\mathrm{e})^{2}$ where $\mathrm{n}$ is the sample size, $\mathrm{N}$ is the population size and $\mathrm{e}$ is the level of precision. This is usually set at 0.05 . Using this formula, a sample of 382 was obtained, which was rounded up to 400 . Thus a sample of 400 female students was drawn using a multistage sampling technique from the total population of 7,632 female undergraduates residing in all the four female halls of residence in the university. In each female hostel, one block of hall was randomly selected by simple balloting. All the students in the block were selected, and those who gave their consent participated in the study. Data was collected from the students using a semi-structured questionnaire over a period of two weeks. The validity of the questionnaire was established through face and content validity criteria by giving it to experts in Nursing, Public health and Obstetrics and Gynaecology for content clarity, scope and relevance to study. Ambiguous items as raised by the experts were reframed and some deleted totally from the instrument. Reliability of the instrument was determined by test-re-test method with alpha correlation of 0.78 . Data collected was collated, sorted out and analyzed using descriptive and inferential statistical techniques such as frequency counts and percentages, bar chart and chi-square in SPSS version 16 at 0.05 level of significance. 


\section{Results}

A total number of 400 respondents participated in this study, all of which were females. The age range was between 15 and 34 years, the mean age was 21 years \pm 2.8 (see Table 1$)$.

Table 1. Socio-demographic characteristics of respondents

\begin{tabular}{lcc}
\hline Socio-demographic Characteristics & Frequency $\mathbf{( N = 4 0 0 )}$ & Percentage \\
\hline Age & & 24.0 \\
$15-19$ & 228 & 57.0 \\
$20-24$ & 50 & 12.5 \\
$25-29$ & 26 & 6.5 \\
$30-34$ & & 96.0 \\
Religion & 384 & 4.0 \\
Christianity & 16 & 25.0 \\
Islam & & 24.0 \\
Year of study & 100 & 14.5 \\
Part 1 & 96 & 20.0 \\
Part 2 & 58 & 15.0 \\
Part 3 & 80 & 1.5 \\
Part 4 & 60 & \\
Part 5 & 6 & 25.0 \\
Part 6 & & 4.0 \\
Ethnicity & 284 & \\
Yoruba & 100 & 1.0 \\
Igbo & 16 & \\
Others & & \\
\hline
\end{tabular}

\subsection{Menstrual data of respondents}

The students' average menarche age was 13.5 years, while majority $(29 \%, \mathrm{n}=116)$ of the respondents attained menarche at the age of 13 years. The average menstrual bleeding duration of respondents was calculated as 4.5 days. The average number of pads used by respondents during each period of menstruation was 5 per day and average menstrual cycle duration of the students was 28 days. Fifty-eight percent $(n=232)$ experienced consistent regular menstrual cycles always, while $22 \%(n=88)$ reported consistent regular menstrual cycle sometimes, the rest $20 \%(80)$ experienced inconsistency in their menstrual cycle.

\subsection{Menstrual disorders experienced by respondents}

Figure 1 shows the menstrual disorders experienced by the respondents. The prevalence of menstrual disorders was $95 \%$ with some of the respondents having combination of two or more of the disorders. The most prevalent menstrual disorder was severe lower abdominal cramp (dysmenorrhoea) during menstruation $(76 \% ; n=304)$. Out of this number, $34 \%(n=$ 104) experienced it always, while $66 \%(\mathrm{n}=200)$ experienced it sometimes. Thirty-six percent $(\mathrm{n}=144)$ experienced low back pain during menstruation. Other menstrual disorders reported by the respondents include absence of menstruation (amenorrhea) in $21 \%(\mathrm{n}=84)$, hypermenorrhoea - menses occurring at more frequent intervals $(19 \% ; \mathrm{n}=76)$, inter menstrual bleeding $(6 \% ; n=24)$ and mennorrhagia - prolonged menstrual period $(21 \% ; n=84)$.

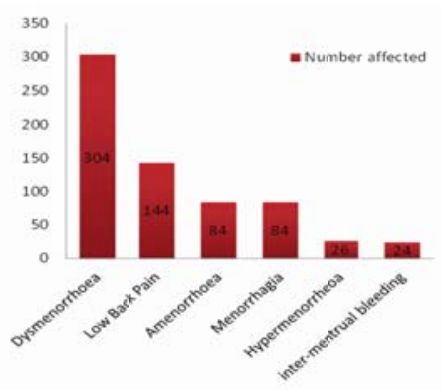

Figure 1. Menstrual disorders experienced by respondents 


\subsection{Knowledge of respondents about menstrual disorders}

Table 2 presents the descriptive analysis of the knowledge of respondents. A 21-item questions package was used to evaluate participants' knowledge of menstrual disorders and its management. A correct option was scored 1 while incorrect response was scored zero. A total score of 21 was obtainable. A score of $70 \%$ and above was judged to be good, $50 \%-69 \%$ fair and $<50 \%$ poor. All the respondents (100\%) recognised that menstrual flow is a monthly occurrence; this was where the highest level of knowledge was recorded. Ninety-three percent $(n=372)$ recognised menstruation as a blood discharge while ninety percent $(n=360)$ knew that applying a heating pad to the abdomen can control pain associated with menstruation. The least area of knowledge recorded was in the area of engagement in exercise $(25 \% ; \mathrm{n}=$ $100)$ as a way of relieving discomfort associated with menstruation. In all, 61\% $(\mathrm{n}=244)$ of the respondents had good knowledge about menstrual disorders and management, $27 \%(\mathrm{n}=108)$ had fair knowledge while $12 \%(\mathrm{n}=48)$ had poor knowledge.

Table 2. Respondents knowledge of menstrual disorders

\begin{tabular}{|c|c|c|c|c|c|c|c|}
\hline \multirow{2}{*}{ Variables } & \multirow{2}{*}{$\begin{array}{l}\text { Correct } \\
\text { Response }\end{array}$} & \multicolumn{2}{|l|}{ Yes } & \multicolumn{2}{|l|}{ No } & \multicolumn{2}{|c|}{ Don't Know } \\
\hline & & $\mathbf{N}$ & $\%$ & $\mathbf{N}$ & $\%$ & $\mathbf{n}$ & $\%$ \\
\hline Menstruation is a bloody discharge from the uterus to the vagina & Yes & 372 & 93 & 16 & 4 & 12 & 3 \\
\hline Menstruation occurs monthly & Yes & 400 & 100 & 0 & 0 & 0 & 0 \\
\hline Heavy menstrual flow is an example of menstrual disorders & Yes & 116 & 29 & 212 & 53 & 72 & 18 \\
\hline $\begin{array}{l}\text { Imbalance in the level of body hormones can cause menstrual } \\
\text { disorders }\end{array}$ & Yes & 280 & 70 & 48 & 12 & 72 & 18 \\
\hline Stress can predispose to menstrual disorders & Yes & 244 & 61 & 32 & 8 & 124 & 31 \\
\hline $\begin{array}{l}\text { Women who have never given birth have a higher risk of } \\
\text { experiencing severe, frequent cramping during menstruation }\end{array}$ & Yes & 328 & 82 & 12 & 3 & 60 & 15 \\
\hline $\begin{array}{l}\text { Consumption of adequate diet could help alleviate some } \\
\text { menstrual disorders }\end{array}$ & Yes & 236 & 59 & 36 & 9 & 128 & 32 \\
\hline Menstrual disorders may be associated with infertility & Yes & 308 & 77 & 36 & 9 & 128 & 32 \\
\hline $\begin{array}{l}\text { Restriction of food intake for the fear of gaining weight can } \\
\text { cause some menstrual problems }\end{array}$ & Yes & 168 & 42 & 68 & 17 & 164 & 41 \\
\hline $\begin{array}{l}\text { Self-initiated vomiting after over-eating can cause menstrual } \\
\text { problems }\end{array}$ & Yes & 228 & 57 & 64 & 16 & 108 & 27 \\
\hline Menstrual disorder is common among younger age women & Yes & 180 & 45 & 80 & 20 & 140 & 35 \\
\hline $\begin{array}{l}\text { Being excessively overweight or underweight can increase the } \\
\text { risk for some menstrual disorders }\end{array}$ & Yes & 104 & 26 & 108 & 27 & 188 & 47 \\
\hline $\begin{array}{l}\text { Some diseases of the reproductive organs can predispose to } \\
\text { menstrual disorders }\end{array}$ & Yes & 248 & 62 & 24 & 6 & 128 & 32 \\
\hline $\begin{array}{l}\text { Some menstrual disorders might signify a form of abnormality } \\
\text { in the reproductive system that need medical attention }\end{array}$ & Yes & 280 & 70 & 12 & 3 & 108 & 27 \\
\hline $\begin{array}{l}\text { Menstruation can occur in other part of the body other than the } \\
\text { uterus }\end{array}$ & Yes & 236 & 59 & 52 & 13 & 112 & 28 \\
\hline $\begin{array}{l}\text { Engaging in exercise can help to relieve some discomforts } \\
\text { associated with menstruation }\end{array}$ & Yes & 100 & 25 & 100 & 25 & 200 & 50 \\
\hline $\begin{array}{l}\text { Applying heating pad to the abdomen can help control pain as a } \\
\text { result of menstruation }\end{array}$ & Yes & 360 & 90 & 20 & 5 & 20 & 5 \\
\hline $\begin{array}{l}\text { Contraceptives can help to relief pain associated with } \\
\text { menstruation }\end{array}$ & Yes & 288 & 72 & 16 & 4 & 96 & 24 \\
\hline $\begin{array}{l}\text { Regulating the intake of sugary foods can help control some } \\
\text { menstrual problems }\end{array}$ & Yes & 176 & 44 & 44 & 11 & 180 & 45 \\
\hline Iron supplements can help control menstrual pain & No & 284 & 71 & 32 & 8 & 84 & 21 \\
\hline $\begin{array}{l}\text { Self-medication may be harmful for management of menstrual } \\
\text { disorders }\end{array}$ & Yes & 208 & 52 & 8 & 2 & 184 & 46 \\
\hline
\end{tabular}




\subsection{Academic and health implications of menstrual disorders}

Figure 2 presents the academic effects of menstrual disorder as found in this study. The highest academic effect recorded was absence from school $(64.5 \% ; n=258)$. This was followed by loss of concentration and feeling of irritation in the same proportion $(63 \% ; n=252)$. These, according to the students, do have significant effect on their relationship with peers and understanding of school lessons taught during the period. The other academic effect was missing of classes $(46 \%$; $n=$ 184). Dysmenorrhoea was found to be significantly associated with school absenteeism among all the menstrual disorders $\left(\chi^{2}=65.79, \mathrm{df}=1, p<.05\right)$.

The health implications of menstrual disorders were presented in Figure 3. Feeling of dizziness was experienced by most of the respondents $(51 \% ; n=204)$ while depression, headache and anxiety were experienced by $42 \%(n=168), 21 \%(n=$ $84)$ and $13 \%(n=52)$ respectively. These, according to the participants, have contributed to missing of classes, tests and sometimes examination.

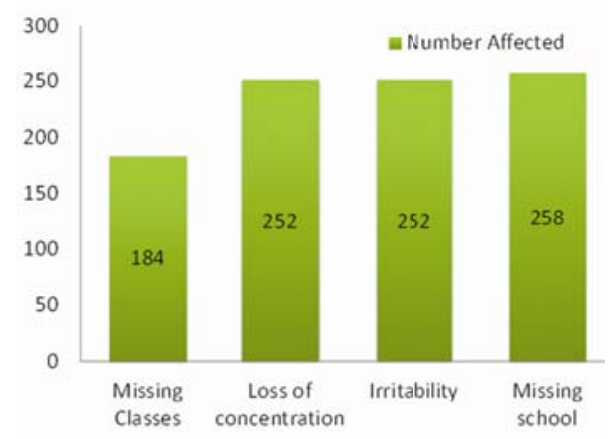

Figure 2. Academic effects of menstrual disorders

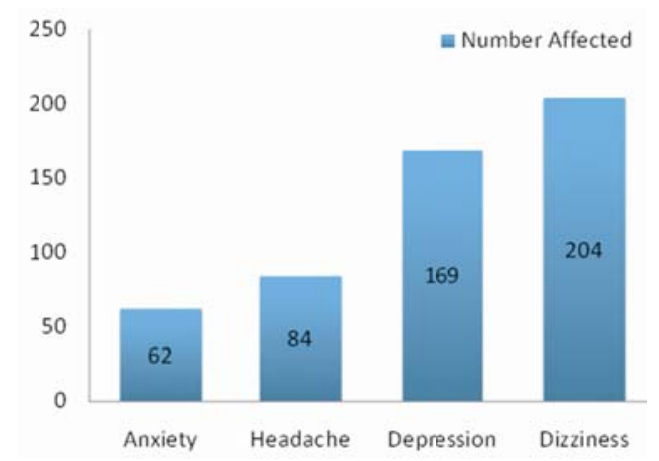

Figure 3. Health Implications of Menstrual Disorders

\subsection{Management pattern adopted for menstrual disorders}

Most common management strategy adopted by the respondents was the use of drugs. Three major class of drugs used students during menses include analgesic $(62 \% ; n=248)$, iron supplement $(17 \% ; n=68)$, and contraceptives $(9 \% ; n=36)$. None of the respondents who used drugs to manage dysmenorrhoea got prescription from doctor or health professional. Other forms of treatment adopted were dietary adjustment some days prior to the onset of menstruation $(53 \%$; $n=212)$, exercise $(48 \% ; n=192)$. Twenty-eight percent $(n=112)$ applied a heating pad to the abdomen, while $5 \%(n=20)$ took herbal remedies to manage their menstrual disorders.

\section{Discussion}

The study showed that majority of the respondents was within the ages of 20 to 24 years. This implied that students surveyed were adults. At this age, they needed adequate knowledge and correct information that can help them make 
informed choice about their health. This also buttressed the submission by Patel and Tanksale ${ }^{[14]}$ that the prevalence of menstrual disorders, especially primary dysmenorrhoea, peaks in the late adolescence and the early 20 s and the incidence falls with increasing age afterwards. The age at menarche found in the study corresponds with previous studies reported in literature $^{[2,3,18]}$.

Evidence from this study also revealed that majority of the respondents had a good knowledge about menstrual disorders and associated risk factors. This finding corroborated a study conducted by Titilayo, et al. ${ }^{[10]}$ on menstrual discomfort and its influence on daily academic activities among undergraduate female students in Nigeria. The result of their study showed that majority of the students had a good understanding of menstrual disorders and discomfort associated with it. It is important to note that the undergraduates were highly knowledgeable about menstruation such that quite a number of them have knowledge that menstruation can occur in other parts of the body other than through the uterus.

Also, findings from this study supported previous studies that dysmenorrhoea was the most prevalent of menstrual disorders among students ${ }^{[2,3,9,19-22]}$. This result however was at variance with Houston et al submission ${ }^{[23]}$ that PMS (Premenstrual syndromes) are the most prevalent menstrual disorders. The association found between dysmenorrhoea and absenteeism from school was similar to what had earlier been reported in this population in Nigeria and other countries ${ }^{[9,21,22,24]}$ that dysmenorrhoea is related to school absenteeism and limitations of academic activities among students. The frequency of dysmenorrhoea observed in this study is comparable to the one found among adolescents and young adults in Nigeria, Turkey, USA ${ }^{[2,9,21,22]}$. Also the prevalence of menorrhagia found in this study was more than the 9\%-14\% reported by Casablanca ${ }^{[25]}$. The percentages of students who missed a school day and individual classes owing to menstrual disorders supported the submission of Di Cintio and Parazzini ${ }^{[20]}$ that menstrual disorders are the leading cause of absenteeism.

The use of analgesics by most of the respondents as a means of pain management was in line with the findings in a study conducted by Adinma \& Adinma ${ }^{[26]}$ who reported that majority of the respondents in their study utilised analgesic for the management of dysmenorrhoea. Common analgesics reportedly being used by respondents include paracetamol, nonsteroidal anti-inflammatory drugs such as ibuprofen and felden. It is worth to note that none of the respondents consulted health personnel for prescription of drugs for management of menstrual disorders. This finding was similar to the submission of Nwakwo et al. ${ }^{[9]}$ who reported that only $16.3 \%$ of the female studied consulted medical doctors before taking analgesics. The same finding was reported by Houston et al. ${ }^{[23]}$ where only $2 \%$ of the teens report receiving information about menstruation from health care practitioners.

Though majority of the respondents affirmed that self medication could be dangerous in managing menstrual disorders; this however did not influence their practice. The implication of this is that there could be misuse of drugs and the associated complications. For example, misuse of NSAIDS such as ibuprofen could result in gastrointestinal bleeding or worsen existing case of peptic ulcer.

More than half of the respondents made dietary adjustment some days prior to menstruation, and this buttressed Simon and Zieve submission ${ }^{[27]}$ that making dietary adjustments starting about 14 days before a period may help some women with certain mild menstrual disorders such as cramping. They further stated that the general guidelines for a healthy diet apply to everyone includes eating plenty of whole grains, fresh fruits and vegetables, and avoiding saturated fats and commercial junk foods. Reducing caffeine, sugar, and alcohol intake may also be beneficial. Other non-pharmacological strategies used by the respondents include heat application and exercise. According to London et al. ${ }^{[28]}$, heat application can promote increase blood flow while regular exercise such as jogging, cycling, swimming and fast spaced walk can help ease menstrual discomforts.

The use of contraceptive constituted the least management strategy employed by respondents. Its use in low dose has been documented to provide relief in more than $90 \%$ of clients ${ }^{[29]}$. Asides ascertaining the source of drugs used by respondents; the study did not explore the source of information on other management strategies used by respondents for the relief of menstrual disorders. 
The academic effects reported in this study were at par with previous findings ${ }^{[9,21,22,24]}$. Most of the health effects reported by the students which include dizziness, headache, depressive and anxiety symptoms have been reported in the literatures as pre-menstrual syndromes. However, none of the respondents reported these as PMS but as real experiences during menses.

This study may be limited by its descriptive nature and small sample size. Also, the fact that not all female undergraduates reside on university campus might have affected the representativeness of the study sample. Therefore, caution should be taking in generalising the result of the study to students who may not be living within university residence and may be influenced by other cultural dictates of the communities of residence. This study did not also explore the influence of the course of study in the university on management or control of discomforts associated with menstrual disorders. Further research is needed to ascertain the influence of individual lifestyles such as diet, engagement in exercise, and menstrual hygiene on menstrual disorders.

\section{I mplications for nursing and recommendation}

The study showed that though female undergraduates were knowledgeable about menstruation, they are yet to be in control of this monthly experience. Majority of them still experience menstrual disorders with the associated health and academic effects. It was also deduced that as a result of difficult menstruation, there is an increase rate of absenteeism and loss of concentration in academic work which may impact on school performances as well as the achievement of their life goals. Thus there is need for regular reproductive health programmes for female undergraduates including information on how to monitor, and manage menstruation. This was in line with Walraven, et al. ${ }^{[30]}$ submissions that information, education and support combined with clinical management of menstrual problems should be core elements of reproductive health programmes. The findings from this study and other previous studies ${ }^{[9,23]}$ reported undermine the role of health care professionals in providing reproductive health information including those that has to do with menstrual health. It is therefore imperative that health care providers most especially nurses increase their anticipatory guidance regarding menstruation and associated disorders. Based on the aforementioned findings of the study, the following recommendations are made:

- Young female undergraduates should be taught premenstrual signs and how to adequately prepare themselves for menstruation to minimise the effect of menstrual disorders through informative, educative and communication (IEC) materials such as handbills which should be included as part of the package for the orientation programme for new undergraduates.

- Enlightenment programmes should be organized periodically by the school health nurses on the various management strategies for menstrual disorders and how to use them effectively.

- Students should be educated on the use of non-prescriptive analgesics and the effects they could have on them. For example, NSAIDS has been reported to have increased risk for gastrointestinal bleeding and ulcers. Nurses should also caution the students on the use of contraceptives without prescription. This is important due to association between long-term use of hormones and possible risk of developing cancer in the future.

- Adequate counselling should be provided by the school nurses to students who experience dysmenorreoa during consultation in the school clinic to avoid or reduce the rate of school absenteeism among them.

- Encourage female undergraduates to seek prompt medical attention to rule out or treat any underlying problem that may be responsible for menstrual disorders or that can interfere with the reproductive health of the undergraduates in later years.

- Nurses as health educators should consistently provide information on the benefits of non-pharmacological self help measures through the use of appropriate teaching aids such as postals, handbills and school bulleting and personal contact with these students during clinic consultation for management of other health problems. 


\section{Conclusion}

The study concluded that despite the good knowledge of menstrual disorders and its management among female undergraduates, majority of them still suffer from the disorders. Early intervention as soon as students are admitted into higher school of learning would be beneficial in helping them to manage this unavoidable experience without any effect on their health and academic work. School health nurses are rightly positioned to offer these interventions. Their expertise should be appropriately utilised by schools to help the young female adapt successfully to menstruation.

\section{References}

[1] Rigon F, Sanctis V, Bernasconi S, Bianchin L, Bona L, Bozzola M., et al. Menstrual Pattern and Menstrual Disorders among Adolescents: an Update of the Italian Data. Italian J of Paed. 2012; 38(38): 1-8. Available from: http://www.ijponline.net/content/38/1/38 Accessed 06032013

[2] Amaza D, Sambo N, Zirahei J, Dalori M, Japhet H, Toyin H. Menstrual Pattern among Female Medical Students in University of Maiduguri, Nigeria. British J of Medicine \& Medical Research. 2012; 2(3): 327-337.

[3] Begum J, Hossain A, Nazneen S. Menstrual Pattern and Common Menstrual Disorders among Students in Dinajpur Medical College. Dinajpurh Med College J. 2009; 2(2): 37-43.

[4] Blondell, RD., Foster, MB. Dave, KC. Disorders of Puberty. Am. FAM Physician. 1999; 60: 209-218.

[5] Cameron, N, Nadgdae, I. Menarche Age in Two Generations of South African Indians. Annals of Hum. Biol. $1996 ; 23: 113-119$. PMid:8702210 http://dx.doi.org/10.1080/03014469600004332

[6] Esimai OA, Esan GO. Awareness of Menstrual Abnormality Amongst College Students in Urban Area of Ile-Ife, Osun State, Nigeria. Indian J of Comm Med. 2010; 35: 63-66. PMid:20606922 http://dx.doi.org/10.4103/0970-0218.62559

[7] Karout N, Hawai S, Altuwaijri S. Prevalence and Pattern of Menstrual Disorders among Lebanese Nursing Students. Eastern Mediterranean Health Journal La Revue de Santé de la Méditerranée orientale. 2012; 18(4): 346-352

[8] Howard WJ. Novak's Textbook of Gynaecology, 12th ed. Philadelphia, Williams Wilkins; 1996.

[9] Harlow SD, Campbell OM. Epidemiology of menstrual disorders in developing countries: a systematic review. Br J Obs Gynae. 2004; 111: 6-16. http://dx.doi.org/10.1111/j.1471-0528.2004.00012.x

[10] Titilayo A, Agunbiade OM, Banjo O, Lawani A. Menstrual Discomfort and It's Influence on Daily Academic Activities and Psychosocial Relationship among Undergraduate Females in Nigeria. Tanzania J of Hlth Research. 2009; 11(4): $181-188$.

[11] Nwakwo TO, Aniebue UU, \& Aniebue PN. Menstrual disorders in Adolescent School Girls in Enugu, Nigeria. J Peadiatr Adolesc Gynecol. 2010; 23(6): 358-63. PMid:21056354 http://dx.doi.org/10.1016/j.jpag.2010.04.001

[12] Kadir RA, Edlund M, Von Mackensen S. The impact of Menstrual Disorders on Quality of Life in Women with Inherited Bleeding Disorders. Haemophilia. 2010; 6: 832-839. PMid:20584085 http://dx.doi.org/10.1111/j.1365-2516.2010.02269.x

[13] Banikarim C, Chacko MR, Kelder SH. Prevalence and Impact of Dysmenorrhoea in Hispanic Female Adolescent. Achives of Paed \& Adolescent Med. 2000; 154: 1226-1229. http://dx.doi.org/10.1001/archpedi.154.12.1226

[14] Patel VM, Tanksale V. The Burden and Determinants of Dysmenorrhoea: A Population Based Survey of 2262 Women in Goa, India. Br J Obs Gynae. 2006; 11(3): 453-463. PMid:16489934 http://dx.doi.org/10.1111/j.1471-0528.2006.00874.x

[15] Harlow SD, Campbell OM. Menstrual Dysfunction: A Missed Opportunity for Improving Reproductive Health in Developing Countries. Repr Health Matters. 2000; 8: 142-147. http://dx.doi.org/10.1016/S0968-8080(00)90016-8

[16] Andrew HA and Roy C. The Nursing Process According to the Roy Adaptation Model. In Roy and Andrews. The Roy Adaptation Model: The Definitive statement. Norwalk, CT, Appleton \& Lange, 1991.

[17] Yamane T. Statistics: An Introductory Analysis. 2nd Ed. New York: Harper and Row, 1967.

[18] Cakir M, Mungan I. Menstrual Patterns and Common Menstrual Disorders among University Students in Turkey. Paediatrics International Journal. 2007; 49(6): 938-942. PMid:18045301 http://dx.doi.org/10.1111/j.1442-200X.2007.02489.x

[19] Loto OM, Adewumi TA, Adewuya, AO. Prevalence and Correlates of Dysmenorrhoea among Nigerian College Women. Australian and New Zealand J Obs Gynae; 2008; 48: 442-444. PMid:18837854 http://dx.doi.org/10.1111/j.1479-828X.2008.00869.x

[20] Di Cintio E, Parazzini F. Dietary Habits, Reproductive and Menstrual Factors and Risk of Dysmenorrhoea. European J Epidemiology. 2002; 13: 925-930. http://dx.doi.org/10.1023/A:1007427928605

[21] Deeb, M \& Kabakian T. Reproductive and Child Health. In Deeb M (ed) Beruit: A Health Profile of 1984-1994. p193. Lebanon: American University of Beirut, 2001. 
[22] Eryilmaz G, Ozdemir F, Pasinlioglu T. Dysmenorrhoea Prevalence among Adolescents in Eastern Turkey: its Effects on School Performance and Relationships with Family and Friends. Paediatr Adolesc Gynecol. 2010; 23(5): 267-72. PMid:20493741 http://dx.doi.org/10.1016/j.jpag.2010.02.009

[23] Houston AM, Abraham A, Huang Z, D’Angelo LJ. Knowledge, Attitudes and Consequences of Menstrual health in Urban Adolescents Females. J Peadiatr Adolesc. Gynecol. 2006; 19(4): 271-5.

[24] Banikarim C, Chacko MR, Kelder SH. Prevalence and Impact of Dysmenorrhoea in Hispanic Female Adolescents. Archives of Paediatrics and Adolescents Medicine. 2000; 154: 1226-229. http://dx.doi.org/10.1001/archpedi.154.12.1226

[25] Casablanca Y. Management of Dysfunctional Uterine Bleeding: Obstetrics and Gynaecology Clinicals North America. 2008; 35(2): 219-234. PMid:18486838 http://dx.doi.org/10.1016/j.ogc.2008.03.001

[26] Adinma ED, Adinma JIB. Perceptions and Practices on Menstruation among Nigerian Secondary School Girls. Afr Reprod Health. 2008; 12(1): 74-83.

[27] Simon H, Zieve D. Menstrual disorders: Lifestyle Changes. 2009. Available from: http://www.umm.edu/patiented/articles/what_home_remedies_severe_menstrual_cramps_000100_7.htm Accessed 21022012.

[28] London ML, Ladewig PW, Ball JW, Bindler RC. Maternal and child Nursing Care. Second Edition p. 75. Pearson Prentice Hall.2007.

[29] Smeltzer SC, Bare BG, Hinkle JL, Cheever KH. Textbook of Medica-Surgical Nursing. Lippincott Williams \& Wilkins. 2008; 1638-1640.

[30] Walraven G, Ekpo G, Coleman R, Scherf C, Morrison L and Harlow S. Menstrual Disorders In Rural Gambia. Studies in Family Planning. 2002; 33: 261-268. PMid:12385087 http://dx.doi.org/10.1111/j.1728-4465.2002.00261.x 